Perri, Juan; Shewbridge, Scott E.; Millet, Richard; Huang, Wilbur; Vargas, Juan; Inamine, Mike; Mahnke, Steve

Site Factor for Use of Velocity-Based EFA Erosion Rates

Verfügbar unter / Available at:

https://hdl.handle.net/20.500.11970/100244

Vorgeschlagene Zitierweise / Suggested citation:

Perri, Juan; Shewbridge, Scott E.; Millet, Richard; Huang, Wilbur; Vargas, Juan; Inamine, Mike; Mahnke, Steve (2010): Site Factor for Use of Velocity-Based EFA Erosion Rates. In: Burns, Susan E.; Bhatia, Shobha K.; Avila, Catherine M. C.; Hunt, Beatrice E. (Hg.): Proceedings 5th International Conference on Scour and Erosion (ICSE-5), November 7-10, 2010, San Francisco, USA. Reston, Va.: American Society of Civil Engineers. S. 172-181. 


\title{
Site Factor for Use of Velocity-Based EFA Erosion Rates
}

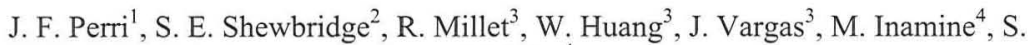 \\ Mahnke $^{4}$
}

${ }^{1}$ Exponent, 500 12th Street, Suite 220, Oakland, CA, 94607 email:

jperri@exponent.com

${ }^{2}$ URS Corporation, 1333 Broadway, Suite 800, Oakland, CA, 94612 email: scott_shewbridge@urscorp.com

${ }^{3}$ URS Corporation, 2870 Gateway Oaks Drive, Suite 150, Sacramento, CA, 95833

email: richard_millet@urscorp.com,wilbur_huang@urscorp.com,

juan_vargas@urscorp.com

${ }^{4}$ Department of Water Resources, P. O. Box 942836, Sacramento, CA 94236 email: inamine@water.ca.gov,gmahnke@water.ca.gov

\begin{abstract}
A mathematical model was developed for estimating riverbed and levee erosion rates based on the results of the Erosion Function Apparatus (EFA) test results of relatively undisturbed soil samples from several California river sites. The mathematical model for erosion estimates was written as a function of shear stresses. An alternative model was used to calculate riverbed and levee erosion rates as a function of channel flow velocity. It is shown that shear stresses imposed by small scale testing apparatuses, such as the EFA, can be significantly larger than those stresses observed in the rivers, for a given flow velocity. Therefore, a 'Site Factor' was developed to account for this difference in stresses, and still maintain the simplicity of a velocitybased erosion model. The velocity-based erosion model can be used as a first order approximation to assess erosion rates under water current loads. Because the use of water velocity is less representative and leads to more uncertainties than using the shear stress, velocity based formulations should be used when shear stress estimates are not readily available. Results of the erosion analyses can then be used to develop a qualitative relative ranking of river bank/berm and levee erosion susceptibility and failure potential.
\end{abstract}

\section{INTRODUCTION}

Historical erosion studies have concentrated in the evaluation of erosion protection. Because the final objective of most of these studies was to evaluate whether erosion was likely to occur, the findings and recommendation of these studied were generally of two types: selection of armor characteristics (e.g., size and shape) to resist the expected loads (wave and/or current) (e.g., Hudson, 1974) or selection of site configurations to reduce the loads at the erodible location (e.g., Dean, 1977; 1991). This lead to recommendation which are, in general, able to predict whether erosion will or will not occur.

The recognition that some erosion processes are beneficial, or too difficult to eliminate, led to the study of equilibrium profiles (e.g., Swart, 1974). The objective was to estimate the equilibrium configuration of sediment transport for natural materials commonly encountered in the coastlines. As a result, the erosion rate of sandy 
materials has been well studied, and predictions of sand erosion can generally be made.

In recent years, an increased amount of research has been devoted to the study of the erosion processes in non-sandy materials (e.g., Aberle et al., 2006; Hanson and Simon, 2001.). Two important types of failures have accelerated this interest: the relatively large number of bridge failures as a result of scour (e.g., Briaud et al., 2003), and levee erosion (e.g., Briaud, 2008).

Evaluation of erosion rates requires the understanding of the loads to be expected in the field, as well as an understanding of the erosion resistance of the erodible materials. This paper presents a simplified procedure developed for the evaluation of levee erosion, based on readily available hydrodynamic and geotechnical information of the levee systems, as well as the results of erosion rates of different materials, as measured in the lab.

\section{EROSION SCREENING PROCESS}

An Erosion Screening Process (ESP) was developed for the DWR Urban Levee Geotechnical Evaluations (ULE) Program. The complete ESP consists of a 3 tier screening process, as presented in Huang et al. (2010). The analyses are completed with the objective of screening the levee vulnerability, and not as a design tool.

Tier 1 consist of an evaluation of the levee geometry, fetch length, and historical geomorphologic performance. If a levee site fails any of the analyses steps in the first tier, or if its historical performance is deemed questionable, the site is evaluated using the second tier of risk factors. In the second tier, comparisons is made between the levee's surface material and river flow velocity and wave action for a given evaluation event. Field reconnaissance is performed to evaluate signs of erosion or unstable conditions, as well as assess the site's vegetation. If a levee site fails any of the three tests in the second tier, it will be advanced to the third tier of factors for further study. On Tier 3, given an evaluation event, an estimate of the erosion potential on the waterside of a levee is made using an Erosion Calculation Spreadsheet. Based on the results of those analyses, the levee section is characterized as having:

1. High erosion risk: The levee site is at immediate risk of an erosional failure during either a flood or a normal flow condition.

2. Moderate erosion risk: The levee site is at risk for failure due to weaknesses, but no immediate threat of failure is apparent.

3. Low erosion risk: Although a geometric deficiency has not been identified, there is either little threat from wind-wave impact and no evidence of historical erosion problems, or the levee's surface material appears adequate to resist velocity and wave loads.

This paper focuses on two alternative approaches to the calculation of erosion rates for Tier 3 of the erosion assessment. The overall methodology for the erosion potential was developed for the U.S. Army Corps of Engineers (USACE) in a risk assessment toolbox (URS, 2007). The methodology currently being implemented builds upon knowledge gained from both previous and concurrent erosion studies conducted by Ayres Associates, USACE, and others. It further adds factors like wind and vegetation. 
In essence, for Tier 3, the erosion potential assessment is conducted using six pieces of information:

1. Levee Geometry;

2. Wind Characteristics;

3. Water/Stream/River Current Characteristics;

Erosion risks to riverine levees will most likely be due to a weakened levee cross section coupled with high flow velocity. In large, open bodies of water like a bypass, wind-wave damage is expected to be a dominant cause of erosion.

\section{EVALUATION OF FLOW INDUCED EROSION: ALTERNATIVE AP- PROACHES}

Because of the complexity of the erosion process, the evaluation of erosion rates was simplified by developing soil erodibility categories. When a soil is identified in the field, absent erosion testing, it can be represented by one of the erosion categories. For this study, and in general agreement with previous studies (e.g., Briaud, 2008; Hanson and Simon, 2001), the following broad erosion categories and typical soils are used:

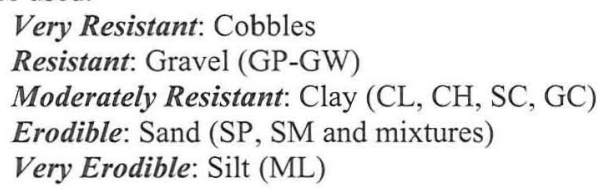

The classification system can be generally presented in terms of erosion rate as a function of velocity, or as a function of shear stress. Although the shear stress formulations is theoretically better founded, there are advantages to representing erosion rates as a function of velocity, as it is often easier to rapidly assess a situation in terms of velocity.

\section{Stress-based formulation}

Several erosion studies have been performed in the past that focus on identifying the erosion parameters and correlating those parameters to formulate an expression (i.e., a physical model) for erosion rates (Hanson and Temple, 2001; Hanson and Cook, 2004). The governing equation (1) for this model is:

$$
\begin{aligned}
& \quad \dot{\varepsilon}=\left(\mathrm{k}\left(\tau-\tau_{\mathrm{c}}\right)\right)>0 \\
& \text { Where: } \\
& \begin{aligned}
\mathrm{k} & =\text { erodibility coefficient or detachment rate coefficient }\left(\mathrm{L}^{3} / \mathrm{M}-\mathrm{T}\right) \\
\tau & =\text { effective hydraulic stress on the soil boundary }\left(\mathrm{M} / \mathrm{L}^{2}\right) \\
\tau_{\mathrm{c}} & =\text { critical shear stress }\left(\mathrm{M} / \mathrm{L}^{2}\right) \text { i.e., shear stress at which erosion starts }
\end{aligned}
\end{aligned}
$$

\section{Where:}

The erosion rate $(\dot{\varepsilon})$ is a function of both hydraulic $(\tau)$ and geotechnical $(\mathrm{k}$, $\tau_{c}$ ) parameters. The effective hydraulic stress, $\tau$, mainly depends on the characteristics of the water-soil boundary, current/stream velocity and/or wind wave height and period. Both $\mathrm{k}$ and $\tau_{\mathrm{c}}$ are functions of the engineering properties of the levee and the foundation materials. 
The estimation of erosion rate due to shear stresses imparted to the levee and its foundation due to current/stream velocity requires information on the hydraulic parameters of stream velocity and water-soil interface roughness. Using the conventional assumption of a logarithmic velocity profile (USACE, 1994), the average hydraulic shear stress due to currents $\left(\tau_{\mathrm{s}}\right)$ can be calculated using Equation 2.

Where:

$$
\tau_{\mathrm{s}}=1 / 2 \rho \mathrm{f}_{\mathrm{c}} \mathrm{v}^{2}
$$

$$
\begin{aligned}
\rho & =\text { mass density of water } \\
f_{c} & =\text { current friction factor (dimensionless) } \\
& =2\left(2.5\left(\ln \left(30 \mathrm{~h} / \mathrm{k}_{\mathrm{b}}\right)-1\right)\right)^{-2} \text { (Danish Hydraulic Institute (DHI), 2006) }
\end{aligned}
$$

Where:

$$
\begin{aligned}
& \mathrm{h}=\text { water depth } \\
& \mathrm{k}_{\mathrm{b}}=\text { bed roughness } \\
& \mathrm{v}=\text { flow speed }
\end{aligned}
$$

\section{Critical Shear Stress}

Erosion rates as a function of shear stress can be measured in the laboratory using one of several devices such as the Erosion Function Apparatus (EFA, Briaud et. $\mathrm{al}, 2001 \mathrm{a}$ and $\mathrm{b}$ ). The critical shear stress, $\tau_{\mathrm{c}}$, is defined as the shear stress corresponding to a rate of erosion of $1 \mathrm{~mm} / \mathrm{hr}$ in the EFA. While useful for analytical studies, this method is impractical for rapid surveys.

Alternatively, the critical shear stress can be estimated using empirical correlations between the critical shear stress and soil index properties. Several empirical correlations between critical shear stress $\left(\tau_{c}\right)$ and soil index properties such as grain size, plasticity index and shear strength are available in the literature to estimate the value of $\tau_{\mathrm{c}}$ (URS, 2007).

As previously mentioned, in order to simplify the analyses, erosion resistance of the levee and foundation material has been divided into five broad classes related

\begin{tabular}{|c|c|c|c|}
\hline Material & ASTM Typical Soil Types & $\begin{array}{l}\text { Critical Shear } \\
\text { Stress, } \tau_{\mathrm{c}}, \mathrm{psf} \\
(\mathrm{Pa})\end{array}$ & $\begin{array}{l}\text { Erodibility Coeffi- } \\
\text { cient, } \mathrm{k}, \mathrm{ft}^{3} / \mathrm{lb}-\mathrm{hr} \\
\left(\mathrm{m}^{3} / \mathrm{kN}-\mathrm{hr}\right)\end{array}$ \\
\hline \multicolumn{4}{|l|}{ Levee/Foundation Material } \\
\hline $\begin{array}{l}\text { Very Resistant } \\
\text { Resistant } \\
\text { Moderately Resistant } \\
\text { Erodible } \\
\text { Very Erodible }\end{array}$ & $\begin{array}{l}\text { Boulders and Cobbles } \\
\text { Gravel (GP-GW) } \\
\text { CLAY (CL, CH, SC, GC) } \\
\text { SAND (SP, SM and mixtures) } \\
\text { SILT (ML) }\end{array}$ & $\begin{array}{c}4.869(233) \\
1.058(50.7) \\
0.094(4.50) \\
0.014(0.670) \\
0.003(0.144)\end{array}$ & $\begin{array}{c}0.005(0.0318) \\
0.021(0.134) \\
0.094(0.598) \\
0.409(2.60) \\
1.867(11.88)\end{array}$ \\
\hline
\end{tabular}
to their ASTM classifications, as shown in Table 1. The erosion calculations used these typical values for critical shear. The values shown in Table 1 are based on the experimental and field-testing results as reported by Briaud et al. (2001a, 2003) and Hanson and Simon (2001).

Table 1 Typical Values for Critical Shear Stress and Coefficient of Erodibility of Soils 


\section{Erodibility Coefficient}

One method to estimate the coefficient of erodibility, $\mathrm{k}$, used in Equation 1, is by performing the jet index test (ASTM D 5852). However performing site-specific tests will be impractical for rapid assessment of conditions.

Therefore, in a manner similar to the method used to evaluate critical shear stresses, to simplify the analyses, erodibility of the levee and foundation materials has been divided into five broad classes related to the material's ASTM classification, as shown in Table 1 . The erosion calculations used typical values for erodibility coefficients. The values, presented in Table 1 , are based on the experimental and fieldtesting results as reported by Briaud et al. (2001a, 2003) and Hanson and Simon (2001).

\section{Velocity-based formulation}

Several erosion studies have been performed in the past that focus on identifying the erosion parameters and correlating those parameters to formulate an expression for erosion rates as a function of velocity (e.g., Briaud, 2008). The governing equation (3) for this model is (a similar formulation can be developed for erosion rate as a function of shear stress):

Where:

$$
\dot{\varepsilon}=\left(\mathrm{V} / \mathrm{V}_{1}\right)^{\alpha}
$$

$\mathrm{V}_{1}=$ Velocity which would cause an erosion rate of 1 unit

$\mathrm{V}=$ Site flow velocity

$\alpha=$ slope of the erosion rate versus velocity (in log-log space)

In this formulation, the erosion rate $(\dot{\varepsilon})$ is a function of both hydraulic $\left(\mathrm{V}, \mathrm{V}_{1}\right)$ and geotechnical $\left(\alpha, V_{1}\right)$ parameters. As will be discussed later in this paper, it is not possible to assign a unique $V_{1}$ for a given soil type. In fact, $V_{1}$ is generally a function of the induced shear stress, and this is a function of multiple parameters (e.g., see Equation 2). In fact, $V_{1}$, mainly depends on the characteristics of the soil type, water depth, water-soil boundary, current/stream velocity and/or wind wave height and period.

\section{Critical Velocity}

Erosion rates as a function of flow velocity can be measured in the laboratory using one of several devices such as the Erosion Function Apparatus (EFA, Briaud et. $\mathrm{al}, 2001 \mathrm{a}$ and $\mathrm{b}$ ). The EFA critical velocity, $\mathrm{V}_{\mathrm{c}-\mathrm{EFA}}$, is defined as the flow velocity corresponding to a rate of erosion of $1 \mathrm{~mm} / \mathrm{hr}$ in the EFA (with this definition and units, $\left.\mathrm{V}_{1}=\mathrm{V}_{\mathrm{c}-\mathrm{EFA}}\right)$.

Alternatively, the critical velocity can be estimated using empirical correlations between the critical velocity and soil index properties. Several empirical correlations between critical velocity $\left(\mathrm{V}_{\mathrm{c}-\mathrm{EFA}}\right)$ and soil index properties such as grain size, plasticity index and shear strength are available in the literature to estimate the value of $\mathrm{V}_{\mathrm{c}-\mathrm{EFA}}$ (e.g., Briaud, 2008). Figure 1 shows one such correlation, as presented by Briaud (2008). 


\section{SITE FACTOR}

The EFA device is calibrated using the Moody chart for estimating the shear stresses induced by the flow velocity:

$$
\tau=1 / 8 \cdot f \cdot \rho \cdot v_{E F A}^{2}
$$

Where $f$ is the friction factor, $\rho$ is the water mass density and $\mathcal{V}_{E F A}$ is the EFA flow velocity.

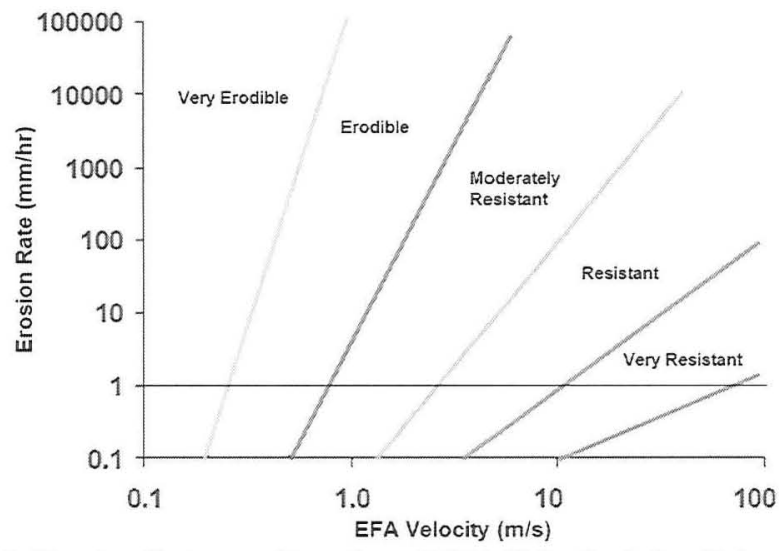

Figure 1. Erosion Rate as a Function of EFA Velocity (after Briaud, 2008)

Because shear stress, rather than flow velocity, is one of the principal loads on the erodible material, in order to develop a velocity-based formulation for erosion rate, it is necessary to estimate the flow velocity which in the field would result in the same shear stresses as in the EFA. Therefore, the objective is to find the river flow velocity ( $v_{h}$, where the subscript $h$ stands for depth) that, for a given material, causes the same hydraulic shear stresses as the EFA velocity $\left(v_{E F A}\right)$. From Equation 2 and 4 follows that:

$$
\tau_{h}=\tau_{E F A} \Rightarrow 1 / 2 \cdot f_{c} \cdot \rho \cdot v_{h}^{2}=1 / 8 \cdot f_{E F A} \cdot \rho \cdot v_{E F A}^{2}
$$

It is possible to show that for the material properties (very erodible to very resistant) and for depth between $5 \mathrm{~cm}$ (EFA) and $30 \mathrm{~m}$, the stresses calculated with the DHI equation (Equation 2) and Darcy's friction formulae (Equation 4), the calculated hydraulic stresses are within approximately $10 \%$. Therefore, to simplify the formulation of the site factor, Equation 5 can be simplified as (Equation 5 can be used for a more rigorous formulation):

$$
\tau_{h}=\tau_{E F A} \Rightarrow 1 / 8 \cdot f_{h} \cdot \rho \cdot v_{h}{ }^{2}=1 / 8 \cdot f_{E F A} \cdot \rho \cdot v_{E F A}^{2}
$$

Therefore:

$$
v_{E F A}=\sqrt{\frac{f_{h}}{f_{E F A}}} \cdot v_{h}=\frac{v_{h}}{S}, \text { Where } \mathrm{S} \text { is the site factor }
$$


For fully developed turbulent flow (it can be shown that for erosion practical cases, and in the EFA, most of the time this is valid), the turbulent portion of the Colebrook equation can be used:

$$
\frac{1}{\sqrt{f}}=-2 \cdot \log \left(\frac{\varepsilon / d}{3.7}\right)
$$

Where $\varepsilon$ is the bed roughness and $d$ is the hydraulic diameter. Therefore, the friction factor can be calculated:

$$
f=\left[-2 \cdot \log \left(\frac{\varepsilon / d}{3.7}\right)\right]^{-2}=[-2 \cdot(\log (\varepsilon)-\log (d)-\log (3.7))]^{-2}
$$

For a rectangular cross section pipe (like the EFA): $d=\frac{4 \cdot A}{p}=\frac{2 \cdot a \cdot b}{(a+b)}$

Where $A$ is the cross-sectional area of the flow, and $p$ is the wetted perimeter.

\section{For the EFA:}

$$
d=\frac{2 \cdot 101.6 \mathrm{~mm} \cdot 50.8 \mathrm{~mm}}{(101.6 \mathrm{~mm}+50.8 \mathrm{~mm})}=67.7 \mathrm{~mm} \approx 1 / 4 . \mathrm{ft}^{\mathrm{ft}}
$$

Therefore, the friction factor in the EFA is given by:

$$
\begin{aligned}
f_{E F A} & =[-2 \cdot\{\log (\varepsilon)-\log (d)-\log (3.7)\}]^{-2}=[-2 \cdot\{\log (\varepsilon)-\log (67.7 m m)-\log (3.7)\}]^{-2} \Rightarrow \\
f_{E F A} & =[-2 \cdot\{\log (\varepsilon[m m])-2.4\}]^{-2}=[-2 \cdot\{\log (\varepsilon[f t])-0.1\}]^{-2}
\end{aligned}
$$

\section{For the river:}

Several formulations can be used to estimate the shear stress for an open channel. As noted above, given the small differences in the calculated stresses, and to simplify the formulation of the Site Factor, S, the shear stresses for an open channel can be approximated with the Darcy's friction formulae and the Colebrook equation (Equation 8).

For simplicity of the calculations (this is not always necessary, and if needed, the hydraulic parameter can be more accurately calculated) assume a rectangular river section, for which the width is about twice the depth. For these conditions:

$$
d=\frac{4 \cdot A}{p}=\frac{4 \cdot(2 \cdot h) \cdot h}{(2 \cdot h+h+h)}=\frac{8 \cdot h^{2}}{4 \cdot h}=2 \cdot h
$$

Therefore, the friction factor in the river can be estimated by:

$$
\begin{aligned}
& f_{h}=[-2 \cdot\{\log (\varepsilon)-\log (d)-\log (3.7)\}]^{-2}=[-2 \cdot\{\log (\varepsilon)-\log (2 \cdot h)-\log (3.7)\}]^{-2} \Rightarrow \\
& f_{h}=[-2 \cdot\{\log (\varepsilon)-\log (h)-0.9\}]^{-2}
\end{aligned}
$$

\section{Site Factor, S:}

Combining Equations 9 and 10 into Equation 7, a simple formulation for the Site Factor can be obtained, as a function of material roughness, $\varepsilon$, and channel depth, $h$ :

$$
S=\sqrt{\frac{f_{E F A}}{f_{h}}}=\sqrt{\frac{[-2 \cdot(\log (\varepsilon[m m])-2.4)]^{-2}}{[-2 \cdot(\log (\varepsilon)-\log (h)-0.9)]^{-2}}} \Rightarrow
$$




$$
S=\sqrt{\frac{f_{E F A}}{f_{h}}}=\frac{\log (\varepsilon[\mathrm{mm}])-\log (h[\mathrm{~mm}])-0.9}{\log (\varepsilon[\mathrm{mm}])-2.4}=\frac{\log (\varepsilon[\mathrm{ft}])-\log (h[\mathrm{ft}])-0.9}{\log (\varepsilon[\mathrm{ft}])-0.1}
$$

Figure 2 shows calculated Site Factors for several idealized conditions. It can be observed, that if the material particle size is considered to be related to its roughness (Briaud et. al, 2001), then the site factor is between 1.5 and about 5 for water depths between $3 \mathrm{~m}(\sim 10 \mathrm{ft})$ and $30 \mathrm{~m}(100 \mathrm{ft})$.

Site Factor, S

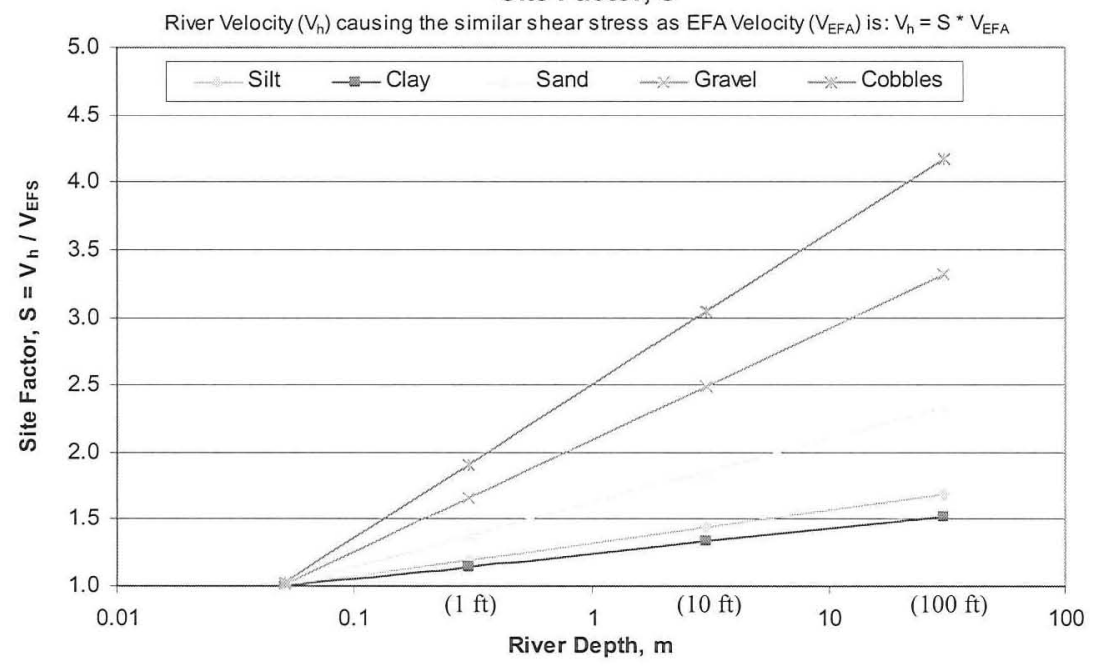

Figure 2. Proposed Site Factor, S, for Various Soil Types

\section{SITE SPECIFIC EXAMPLE CALCULATION}

The following site-specific example is based on a known channel geometry and EFA test results obtained for the ULE Program during a soil sample testing program:

1. $6 \mathrm{~m}(\sim 20 \mathrm{ft})$ deep channel (approximately rectangular river section),

2. Roughness of $1.5 \mathrm{~mm}(\sim 0.005 \mathrm{ft})$, appropriate for Silts and Clays,

3. EFA results for Silts measured in the DWR program (Shewbridge et al., 2010): $\mathrm{V}_{1}=0.157 \mathrm{~m} / \mathrm{s}, \alpha=2.7$ (Equation 3 and Figure 3 - Figure 3 shows EFA test results on Silt and Clay samples from the ULE Program)

4. River velocity of $3 \mathrm{~m} / \mathrm{s}(\sim 10 \mathrm{ft} / \mathrm{s})$. appropriate for the American river for the 100-yr event.

From Equation 11, a Site factor is calculated as follows:

$$
S=\sqrt{\frac{f_{E F A}}{f_{h}}}=\frac{\log (\varepsilon[\mathrm{mm}])-\log (h[\mathrm{~mm}])-0.9}{\log (\varepsilon[\mathrm{mm}])-2.4}=\frac{\log (1.5)-\log (6000)-0.9}{\log (1.5)-2.4} \approx 2
$$


Therefore, the EFA velocity that would result in the same stresses in the EFA sample as in the river bed can be calculated:

$$
v_{E F A}=\frac{v_{h}}{S}=\frac{3 \mathrm{~m} / \mathrm{s}}{2}=1.5 \mathrm{~m} / \mathrm{s} \approx 5 \mathrm{ft} / \mathrm{s}
$$

Using Equation 3 with the EFA results adjusted by the site factor, the erosion rate in the river, for this site-specific example, is calculated as $0.44 \mathrm{~m} / \mathrm{hr}(\sim 1 \mathrm{ft} / \mathrm{hr})$, compared to $2.9 \mathrm{~m} / \mathrm{hr}(\sim 10 \mathrm{ft} / \mathrm{hr})$ using Equation 3 with the EFA results directly, without a site factor correction.

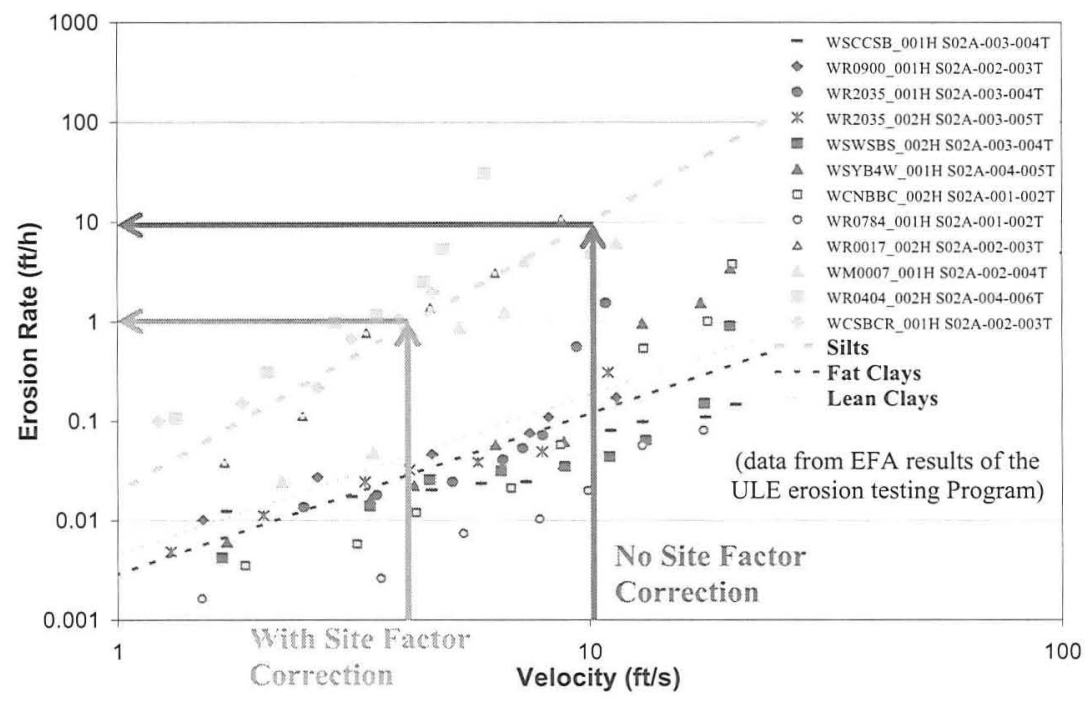

Figure 3. Example Erosion Rate Calculation with Site Factor Use (data from EFA results of the ULE erosion testing Program)

\section{CONCLUSIONS}

A site factor to allow for the use of a velocity-based formulation for the calculation of erosion rates in the field was developed and presented. A site factor of 2 implies that the river velocity must be twice the EFA velocity to cause the same shear stresses on the soil. A site factor (or other correction) is required if a velocity based formulation is used to estimate erosion rates in the field, based on laboratory test results. In fact, shear stresses imposed by the EFA for a given flow velocity can be more than an order of magnitude larger than the shear stresses imposed at the riverbed by the same flow velocity. Therefore, for a given flow velocity, velocity-based erosion rates can be more than an order of magnitude larger in the EFA than in the field (specially for Silts).

Stress-based formulations for the erosion rate calculations do not require a site factor. Other factors further compounding the difference between EFA and river condition may include riverbed cross-section (resulting in varying velocity profiles) and vegetation, which are not accounted for in the present formulation. 


\section{REFERENCES}

Aberle, J., Nikora, V., Walters R. 2006. Data Interpretation for In Situ Measurements of Cohesive Sediment Erosion. Journal of Hydraulic Engineering. ASCE, Bol. 132. pp. 581-588.

Briaud, J.-L. 2008. "Case Histories in Soil and Rock Erosion: Woodrow Wilson Bridge, Brazos River Meander, Normandy Cliffs, and New Orleans Levees", The 9th Ralph B. Peck Lecture, Journal of Geotechnical and Geoenvironmental Engineering, Vol 134, ASCE, Reston Virginia, USA.

Briaud, J.-L., Chen, H.C., Li Y., Nurtjahyo, P., Wang, J. 2003. Complex Pier Scour and Contraction Scour in Cohesive Soils. National Cooperative Highway Research Program Report.

Briaud, J.-L., Ting F., Chen, H.C., Cao Y., Han S. -W., Kwak K. 2001a. Erosion Function Apparatus for Scour Rate Predictions. Journal of Geotechnical and Geoenvironmental Engineering. ASCE, Vol. 127, N. 2, pp. 105-113.

Briaud, J.-L., Ting, F., Chen, H.C., Gudavalli, S.R., Perugu, S.B., Wei, G. 2001 b. Apparatus and Methods for Prediction of Scour Related Information in Soils. United States Patent, Patent No. US 6,260,409.

Danish Hydraulic Institute (DHI). 2006. Mike 21 Flow Model. Mud Transport Module, Scientific Background. DHI, Denmark.

Dean, R.G. "Equilibrium beach profiles: characteristics and applications", Journal of Coastal Research 7(1), p. 53-84, 1991

Dean, R.G. "Equilibrium beach profiles: U,S Atlantics and Gulf Coasts" Ocean Engineering report No.12, University of Delaware, Department of Civil Engineering, Newark, 1977.

Hanson, G.H., Temple, D.M. 2001. Performance of Bare-Earth and Vegetated Steep Channels Under Long-Duration Flows. Presented at the 2001 ASAE Annual Meeting. ASAE Paper No. 012157.

Hanson, G.J., Cook, KR. 2004. Apparatus, Test Procedures, and Analytical Methods to Measure Soil Erodibility in Situ. Applied Engineering in Agriculture.

American Society of Agricultural Engineers, Vol. 20, No. 4, pp. 455-462.

Hanson, G.J., Simon, A. 2001. Erodibility of Cohesive Streambeds in the Loess Area of the Midwestern USA. Hydrological Processes. V. 15 No 1. pp. 23-38.

Huang, W., Millet, R., Shewbridge, S., Perri, J. F., Vargas, J., Inamine, M., Mahnke, M. 2010. Levee Erosion Screening Process. ICSE5. Procedures.

Shewbridge, S., Perri, J. F., Mineart, P., Millet, R., Huang, W., Vargas, J., Inamine, M., Mahnke, M. 2010. Erosion Screening Process to assess the potential for erosion failure on a levee's waterside slope. ICSE5. Procedures.

Swart, D.H. 1974. Offshore Sediment Transport and Equilibrium Beach Profiles. Delft Hydraulic Lab. Publication 131. Delft University. Delft. 302 pp.

United States Army Corps of Engineers. 1994. Hydraulic Design of Flood Control Channels. EM 1110-2-1601. June 30.

URS. 2007. User's Manual, Erosion Toolbox: Levee Risk Assessment Methodology, USACE Nation Wide Levee Assessment. December. 